\title{
A EPISIOTOMIA NA PERCEPÇÃO DE PUÉRPERAS
}

\author{
Vanessa Aparecida Rezende Dengo ${ }^{1}$, Rosana dos Santos Silva², Silvana Regina Rossi Kissula Souza ${ }^{3}$, Juliane \\ Dias Aldrighi ${ }^{4}$, Marilene Loewen Wall ${ }^{5}$, Franciane Zabloski Vieira Cancela ${ }^{2}$
}

RESUMO: O presente estudo teve como objetivo conhecer como a parturiente foi informada e orientada quanto à realização da episiotomia no parto. Trata-se de uma pesquisa qualitativa e descritiva. Participaram do estudo oito puérperas, internadas no alojamento conjunto de uma maternidade pública do Estado do Paraná. A coleta de dados foi realizada em fevereiro de 2015 por meio de entrevista semiestruturada. Os dados foram analisados com base na análise temática, emergindo os seguintes temas: Episiotomia: o conhecido desconhecido; "Cortando" o direito de escolha; Desconhecendo as consequências da episiotomia. Observou-se que as mulheres não são informadas e orientadas a respeito da realização da episiotomia, o que leva ao entendimento errôneo sobre esta prática e à limitação do direito de escolha da mulher. Isso indica a necessidade de ampliação do conhecimento e do resgate da autonomia da mulher no processo de parto e nascimento.

DESCRITORES: Episiotomia; Direitos Sexuais e Reprodutivos; Enfermagem Obstétrica; Autonomia Pessoal.

\section{PUERPERAL WOMEN'S PERCEPTIONS ABOUT EPISIOTOMY}

\begin{abstract}
The objective of the present study was to know how parturient women were informed and guided regarding the undertaking of episiotomy during childbirth. A qualitative and descriptive study was conducted with eight puerperal women hospitalized in a rooming-in of a public maternity hospital in the state of Paraná. Data were collected in February 2015, by means of semi-structured interviews. The following topics emerged from the data analyzed based on thematic analysis: Episiotomy: the known unknown; "Cutting" the right of choice; Being unaware of the episiotomy's consequences. Women were not informed and guided regarding the episiotomy's procedure, which leads to a misunderstanding about this practice and the limitation of women's right of choice. This shows the need for increasing knowledge and rescuing women's autonomy during the childbirth and birth process. DESCRIPTORS: Episiotomy; Sexual and Reproductive Rights; Obstetric Nursing; Personal Autonomy.
\end{abstract}

\section{LA EPISIOTOMÍA EN LA PERCEPCIÓN DE LAS PUÉRPERAS}

RESUMEN: El objetivo del presente estudio fue conocer cómo fue informada y orientada la parturiente respecto de la realización de episiotomía en el parto. Investigación cualitativa, descriptiva. Participaron del estudio ocho puérperas, internadas en alojamiento conjunto de una maternidad pública del Estado de Paraná. Datos recolectados en febrero de 2015 mediante entrevista semiestructurada, posteriormente analizados utilizándose análisis temático, habiendo surgido los siguientes temas: Episiotomía: el conocido desconocido; "Cortando" el derecho de elegir; El desconocimiento de las consecuencias de la episiotomía. Se observó que las mujeres no son informadas ni orientadas respecto de la realización de la episiotomía, lo que lleva a un entendimiento erróneo sobre la práctica y a la limitación del derecho a elección de la mujer. Esto indica la necesidad de ampliación del conocimiento y del rescate de la autonomía de la mujer en el proceso de parto y nacimiento.

DESCRIPTORES: Episiotomía; Derechos Sexuales y Reproductivos; Enfermería Obstétrica; Autonomía Personal.

${ }^{1}$ Enfermeira. Universidade Federal do Paraná. Curitiba, PR, Brasil.

${ }^{2}$ Discente de Enfermagem. Universidade Federal do Paraná. Curitiba, PR, Brasil.

${ }^{3}$ Enfermeira. Doutora em Enfermagem. Docente de Enfermagem da Universidade Federal do Paraná. Curitiba, PR, Brasil.

${ }^{4}$ Enfermeira. Mestranda em Enfermagem. Universidade Federal do Paraná. Curitiba, PR, Brasil.

${ }^{5}$ Enfermeira. Doutora em Enfermagem. Docente do Departamento e Pós-graduação em Enfermagem da Universidade Federal do Paraná. Curitiba, PR, Brasil. 


\section{INTRODUÇÃO}

A episiotomia é uma incisão cirúrgica realizada a fim de aumentar o períneo para a passagem do feto no momento do parto ${ }^{(1-2)}$. Este procedimento tem sido utilizado com a prerrogativa de prevenir lacerações perineais, favorecer a liberação do feto, evitar danos ao assoalho pélvico, prolapsos genitais, incontinência urinária futura e relaxamento da musculatura pélvica, além de reduzir o risco de morbimortalidade infantil(2-4).

Entretanto, na literatura, não há evidências suficientes para sustentar os benefícios da prática rotineira da episiotomia. O que se observa é que o uso rotineiro desta prática não previne lacerações perineais graves e aumenta a taxa de infecção e riscos de perda sanguínea, além de causar desconforto e aumentar o tempo de recuperação da mulher no pós-parto, sendo seu emprego associado a resultados sem benefícios para a mulher, e a morbidades maternas no período puerperal, como interferência na mobilidade e presença de dor local moderada ${ }^{(2-3,5)}$.

No Manual Maternidade Segura da Organização Mundial de Saúde (OMS), a episiotomia é classificada como uma prática frequentemente utilizada de modo inadequado, podendo ser indicada ocasionalmente e com limitações, pois existem evidências de que seu uso rotineiro pode causar danos $^{(6)}$.

Apesar das evidências demonstrarem as desvantagens da realização da episiotomia de forma rotineira, sua prática ainda é comum no Brasil. É realizada em até $94 \%$ dos partos vaginais, enquanto que a OMS prevê uma taxa aceitável entre 10 e 15\%, sendo considerado um dos procedimentos cirúrgicos de maior prevalência no sistema público brasileiro ${ }^{(1,3,7)}$.

Esses altos índices de realização da episiotomia se justificam devido à formação estar alicerçada no modelo tecnocrático de assistência ao parto, pautado muitas vezes em normas e rotinas sedimentadas no cotidiano da prática profissional. Assim, muitos profissionais responsáveis pela realização do parto continuam realizando tal procedimento sem o consentimento ou informação adequados à parturiente ${ }^{(7)}$, o que caracteriza violação dos direitos sexuais e reprodutivos ${ }^{(3)}$. Nesse sentido, essa postura intervencionista prejudica a mulher sobre decidir sobre seu corpo no momento do parto ${ }^{(7)}$. Quando as mulheres têm informação sobre a realização da episiotomia e conhecem o potencial de seus corpos, elas percebem que são submetidas a uma lesão que na maioria das vezes pode ser evitada e até recusada ${ }^{(1,3)}$. Além disso, a omissão da informação no ato da realização da episiotomia constitui desvalorização da opinião e consentimento da mulher, que é uma prática contrária ao que defende o modelo humanizado de atenção ao parto ${ }^{(7)}$.

Desde os anos de 1990, há uma luta de diversos movimentos pela humanização do parto e pela utilização de boas práticas durante o período perinatal. Apesar de existirem orientações governamentais que respaldam a atuação para a humanização do parto e nascimento, ainda percebe-se que há um descompasso entre o que é indicado pela OMS e o que é realizado pelos serviços de saúde ${ }^{(7)}$. É premente que os profissionais realizem suas práticas com base em evidências científicas, a fim de contribuir com a melhoria da assistência e respeitar os direitos sexuais e reprodutivos das mulheres.

Em vista dessas questões, emergiu a inquietação: Como as mulheres são orientadas e informadas quanto à realização da episiotomia? Desenvolveu-se este estudo com o objetivo de conhecer como a parturiente é informada e orientada quanto à realização da episiotomia em uma maternidade pública do Sul do Brasil.

\section{- MÉTODO}

Trata-se de estudo qualitativo e descritivo, que tem por objetivo responder a questões particulares, com um nível de realidade que não pode ser quantificado, trabalhando com o universo dos motivos, valores, atitudes e significados, em que seu objeto de pesquisa dificilmente pode ser traduzido em indicadores quantitativos ${ }^{(8)}$.

O presente estudo foi realizado em uma maternidade pública do Sul do Brasil. Participaram oito puérperas que estavam internadas no alojamento conjunto da maternidade nos meses de março e abril 
de 2015. Os critérios de inclusão no estudo foram: puérperas submetidas à episiotomia por ocasião do parto vaginal, maiores de 18 anos. Os critérios de exclusão foram: puérperas submetidas à cesárea ou que tiveram natimortos.

Para a coleta dos dados, a pesquisadora, primeiramente, fez o convite à puérpera para a participação do estudo, com a apresentação dos objetivos e do Termo de Consentimento Livre e Esclarecido. Nesse momento foram explicados os aspectos éticos da Resolução $n^{\circ} 466 / 2012^{(9)}$. A coleta de dados foi realizada por meio de entrevista semiestruturada, em sala privativa, durante a internação da puérpera. As entrevistas foram gravadas e transcritas integralmente e as informações que poderiam identificar as participantes foram omitidas. Para isso, as mulheres foram identificadas com a letra " $M$ " e o respectivo número, indicando a ordem em que ocorreram as entrevistas.

Os dados foram analisados e interpretados pela técnica de análise de conteúdo temática, que está relacionada com a noção de tema e ligada a uma afirmação sobre determinado assunto ${ }^{(8)}$.

Primeiramente foi realizada uma pré-análise do material obtido por meio da transcrição das entrevistas e leitura destas. Em seguida, os dados foram analisados por meio da seleção de trechos significativos e classificação das entrevistas por eixos temáticos, buscando temas em torno dos quais podem ser discutidas as diferentes partes dos textos analisados. Após esta categorização, foi realizada a interpretação dos resultados, utilizando o material científico disponível ${ }^{(8)}$.

O Projeto de Pesquisa foi submetido e aprovado pelo Comitê de Ética em Pesquisa em 12/01/2015 sob o Parecer $n^{\circ}$ 931.537, alocado na Plataforma Brasil, respeitando as normas da Resolução $n^{\circ} 466 / 2012$ para Pesquisa envolvendo Seres Humanos ${ }^{(9)}$.

\section{RESULTADOS}

Participaram do estudo oito mulheres que atenderam aos critérios de inclusão, com idade entre 18 e 37 anos. Seis delas possuíam o $2^{\circ}$ grau completo e todas realizaram pré-natal. Apenas uma fez uso de fórcipe no parto atual e já tinha sido submetida à episiotomia anteriormente.

Os temas identificados conforme aproximação entre os discursos das participantes do estudo foram: Episiotomia: o conhecido desconhecido; "Cortando" o direito de escolha; Desconhecendo as consequências da episiotomia.

\section{Episiotomia: o conhecido desconhecido}

Quatro puérperas relataram não ter recebido qualquer informação sobre o procedimento antes ou durante o parto. Uma das entrevistadas nunca tinha ouvido falar na episiotomia até então e algumas já tinham ouvido falar no procedimento, porém, não sabiam exatamente do que se tratava:

Não sabia [o que era episiotomia], fiquei sabendo na hora. Eu achei que era só o nenê sair, não precisava ponto. (M3)

É um cortezinho [...]. É só um corte que eles fazem ali, mas nunca ouvi falar assim, tipo o nome específico deste corte. (M4)

Pra mim é normal, né, eu não sei. Eu acredito que em todo parto tem isso. (M6)

Não. Não sabia como era. Faz um rasgadinho assim, né? Foi por isso, pra fechar mais [...] Às vezes acho que pela força, não sei. Talvez acaba abrindo um pouquinho mais, eu acho que é isso. (M8)

Em relação aos motivos pelos quais foram submetidas à episiotomia, as entrevistadas alegaram que o profissional fez o procedimento para ajudá-las na retirada do bebê, evitando riscos e facilitando o processo de parto, como podemos observar nos discursos a seguir:

[...] daí pra me ajudar, ela falou assim que não é em todos os casos que ela faz o procedimento, mas que ela ia aplicar a anestesia e ia fazer o corte. (M1) 
Ele disse que ia fazer um cortezinho pra ajudar no nascimento do bebê. Pra não demorar muito pra nascer [...]. (M5)

Ele falou que ia ter que fazer o corte pra ajudar a tirar ele. Ele só me falou que ia fazer pra ajudar. (M7)

Outras situações identificadas nos discursos das puérperas a respeito do motivo pelo qual foi realizada a episiotomia relacionam-se com a incapacidade do corpo feminino de parir naturalmente, ou seja, o fato de a vagina não se estender suficientemente para a passagem do feto, associada ao tamanho deste, o que impossibilitaria o parto natural:

[...] eu acho que ela achou que o bebê era um pouco maior, sabe? (M1)

[...] aí eu pensei, porque ele na ecografia deu 3580 g, e 49 cm, daí eu meio que imaginava que ele ia nascer com esse peso e ter que fazer o cortinho. (M2)

Ele falou que tinha porque o nenê acho que abriu muito. (M3)

Acho que é muito pequeno ali pra passar a criança, daí acho que não dava. Meu espaço ali era muito pequeno. (M4)

Ele disse que a cabeça era muito grande. (M5)

Pra ajudar o nenê nascer? Pra ajudar a passar a cabeça do nenê eu acho, né, só pode. (M6)

Eu sabia que... já ouvi falar, né, que às vezes, quando não sai, tem que dar um cortezinho. Mas acredito que seja só nessa hora, né. (M7)

\section{"Cortando" o direito de escolha}

Seis puérperas não foram questionadas em relação ao seu consentimento para a realização do procedimento e algumas só perceberam que haviam sido submetidas à episiotomia no momento da sutura:

Para mim a médica avisou na hora que estava fazendo, que ia precisar, ia levar uma anestesia, e daí ela fez o corte. (M1)

Eu nem senti o corte. Depois que eu vi que estavam dando os pontos [...]. Não falaram nada. Eu até achei que tinha rasgado sozinho, dado uma rasgadinha sozinho. Não me informaram de nada. (M2)

Não sabia, fiquei sabendo na hora. Ele falou que tinha que fazer. (M3)

Ele falou: "Vou fazer um cortezinho.". (M5)

Não falaram nada. A não ser que falaram pra minha cunhada, pra mim não [...] Eu senti na hora que fizeram. Eu senti na hora que estavam costurando. Daí eu senti um fio puxando. (M6)

Eu senti, assim, ele dando os pontinhos. (M8)

\section{Desconhecendo as consequências da episiotomia}

As entrevistadas não tiveram muitas queixas em relação ao procedimento, porém quatro delas relataram desconforto, dor leve e ardência:

Tirando o incômodo do ponto, tá bom. Não é dor, é só um desconforto. Ardência eu tenho, acho que de tanto fazer força. Pra ir no banheiro tá normal, não ardeu não. (M2)

Não tô sentindo dor, só pra mover, pra me virar assim dá uma dorzinha, pouca, mas nada de mais mesmo. (M3)

É uma região que fica ali dolorida e tal, mas agora é a questão dos cuidados pra cicatrizar, tudo certinho. Mas, até então, não está me incomodando. (M4) 
Tá bem, não tô sentindo nada. Nada, nada, não sinto os pontos. Sempre arde um pouquinho, daí lava com sabão. (M8)

\section{DISCUSSÃO}

As mulheres deste estudo receberam pouca ou nenhuma informação sobre a episiotomia, mesmo no momento do parto ou durante o pré-natal, demonstrando a carência de conhecimento sobre o procedimento. Esse fato ratifica o que é encontrado na literatura, em que a maioria das mulheres submetidas à episiotomia não recebe qualquer informação sobre o procedimento em momento algum antes do parto, desconhecendo os riscos a que são sujeitas ${ }^{(10)}$.

Esse fato reflete a qualidade das informações e orientações fornecidas durante o pré-natal em relação ao processo de parto e nascimento, pois esse é o momento de preparar a mulher para viver a gestação e o parto de forma positiva e integradora ${ }^{(11)}$. A educação em saúde realizada pelos profissionais durante o pré-natal inclui o acesso a informações pertinentes quanto às possíveis intervenções durante o processo de parto, sendo fundamentais não só para a aquisição de conhecimento sobre gestar e parir, mas também para o seu fortalecimento como ser humano.

Quando o atendimento pré-natal é feito de forma contextualizada e qualificada, pode proporcionar a prevenção de intercorrências durante o parto. Além disso, é direito das gestantes serem informadas sobre os cuidados de saúde a que serão submetidas, para assim participarem das decisões que influenciam suas vidas ${ }^{(11)}$.

Por meio do acesso à informação, pode-se resgatar a autonomia da mulher no processo de parto e nascimento, sendo este um dos grandes desafios da assistência à saúde da mulher ${ }^{(7)}$. As mulheres anseiam em receber informações durante a assistência pré-natal, e ao mesmo tempo acabam sendo multiplicadoras do conhecimento por meio da troca de informações com outras mulheres, sendo assim transformadoras de opiniões, pois ao adquirir informações consequentemente passam a ter maior domínio sobre seu corpo e poder de decisão sobre sua gravidez ${ }^{(11)}$.

Dessa forma, o Ministério da Saúde (MS), por meio de iniciativas, vem estimulando a atuação da enfermeira obstetra tanto no pré-natal quanto no parto, propondo mudanças no modelo de atenção ao parto e nascimento. A formação dessa profissional é voltada a uma assistência de enfermagem de caráter humanizado que respeita a fisiologia de todo o processo de parto e nascimento, valoriza a informação como forma de promover o empoderamento, partilha as responsabilidades e incentiva a autonomia das mulheres ${ }^{(12-13)}$. Destaca-se que a enfermeira obstetra, profissional especializado comprometido com a qualidade do cuidado à gestante, parturiente e puérpera, tem em seu exercício legal o respaldo para assistir a essa população com vistas a empoderar as mulheres para que a vivência da gestação, parto e pós-parto seja de forma plena, com dignidade, segurança e autonomia ${ }^{(14)}$.

Pode-se afirmar que neste estudo a percepção das mulheres entrevistadas é de que os seus corpos não são capazes de parir naturalmente, necessitando de ajuda profissional, neste caso, do médico, para ampliar o canal de parto por meio da episiotomia e possibilitar a passagem do feto com menores riscos. Isso demonstra como a falta de informação e o desconhecimento das mulheres em relação ao seu próprio corpo e à episiotomia trazem consequências importantes, principalmente no que se refere ao domínio/controle exercido pelo profissional sobre o corpo da parturiente, por meio da ideia de que o procedimento é fundamental para ajudá-las em um processo que é natural.

No paradigma tecnocrático, acredita-se que o corpo feminino é um desvio do masculino pela concepção de uma sociedade patriarcal e entendido como defeituoso e imprevisível, necessitando, dessa forma, da manipulação masculina para poder ser organizado. Assim, o parto requer a intervenção hábil e rápida do profissional, tornando o corpo da mãe uma máquina. Por meio desta mecanização do corpo, o paciente é visto como objeto dos cuidados médicos, liberando o profissional do sentimento de responsabilidade diante do sujeito ${ }^{(15)}$.

Em estudo realizado em Pernambuco com 522 puérperas, no Nordeste do Brasil, verificou-se predominância de partos com episiotomia nos partos de primíparas atendidas por médicos plantonistas, bem como o uso de fórceps. Encontrou-se também que a posição supina estava presente na maioria 
dos casos em que ocorreu episiotomia, posição esta que sabidamente desfavorece a descida do bebê durante o trabalho de parto, levando à crença de que é necessária a realização do procedimento $^{(4)}$. Percebe-se neste estudo que o uso da episiotomia está associado a outras práticas frequentemente utilizadas de modo inadequado, como o parto instrumentalizado/cirúrgico, posição supina durante o parto e prolongamento da fase expulsiva consolidando e refletindo o controle médico no momento do parto e privando a mulher de exercer seu protagonismo.

Destaca-se ainda que o procedimento episiotomia foi realizado em menos de $8 \%$ dos partos assistidos por enfermeiras obstetras, e de aproximadamente $30 \%$ em partos assistidos por médicos ${ }^{(4)}$. Este estudo corrobora com a revisão sistemática disponível na Cochrane Library, que aponta um risco de episiotomia $20 \%$ menor em partos realizados por enfermeiras obstetras ${ }^{(16)}$. Em outro estudo, realizado em 2010 no Rio de Janeiro, que analisou 1287 registros de partos normais atendidos por enfermeiras obstetras, identificou-se que $16 \%$ das mulheres foram submetidas à episiotomia, a posição vertical foi identificada em $78 \%$ dos partos e em $89 \%$ das parturientes foram utilizados métodos não invasivos e não farmacológicos para proporcionar conforto e alívio da dor ${ }^{(17)}$. Observa-se mais uma vez que a enfermagem respeita os preceitos da OMS de promover o mínimo de intervenções possíveis, estimulando o resgate da valorização do parto fisiológico ${ }^{(6)}$.

Outra questão importante a destacar é a falta de consentimento prévio, pois, de acordo com os discursos das puérperas, a maior parte delas não foi consultada sobre a realização do procedimento, e, ainda, algumas só perceberam que haviam sido submetidas à episiotomia no momento em que o profissional estava realizando a episiorrafia.

Muitos profissionais afirmam que a episiotomia é o único procedimento cirúrgico que pode ser realizado sem o consentimento da parturiente. No entanto, por se tratar de um ato cirúrgico, a episiotomia deve ser informada e autorizada pela mulher antes de sua realização, e, ainda, devem ser apontados os possíveis riscos e benefícios do procedimento, sem que haja violação dos direitos sexuais e reprodutivos ${ }^{(10)}$. O planejamento em relação a esta e outras intervenções deve fazer parte do plano de parto ${ }^{(10,18)}$.

Estudo sobre a ocorrência e fatores associados à episiotomia, realizado em 2012 em um hospital público de Pernambuco, declara que as mulheres não experienciam o parto como algo fisiológico e fortalecedor, devido ao excesso de intervenções e medicalização. Os autores reforçam que, em geral, as mulheres não recebem qualquer informação sobre o procedimento durante a gravidez e parto, e esta prática acaba frequentemente sendo realizada sem consentimento ${ }^{(3)}$. Outro estudo de revisão de literatura realizada no Rio Grande do Norte em 2011, acrescenta que a violação dos direitos e a falta de autonomia podem comprometer o estado psíquico e emocional da parturiente, além de privar o direito de controle sobre o seu corpo e desrespeitar sua individualidade ${ }^{(10)}$.

Ainda há um longo caminho a ser percorrido pela mulher no que se refere à sua autonomia decisória, pois, no momento, ela se encontra submetida às escolhas dos profissionais. O direito de decisão deve ser preservado e a escolha informada deve ser estimulada pelos profissionais.

Em relação às consequências da episiotomia, a maior parte das entrevistadas não teve muitas queixas em relação ao procedimento, no entanto, os discursos mostram algumas situações de desconforto e incômodo no local, que devem ser consideradas.

A episiotomia é um procedimento invasivo e, na medida em que não se dá voz à mulher para a decisão de fazê-la ou não, ele torna-se invasivo não somente ao fisiológico, mas ao aspecto psicológico também. A mulher pode ter lembranças desagradáveis de dor, desconforto, receio e vergonha de seu companheiro devido ao aspecto atual da região genital (um dos símbolos de sua sexualidade), medo de retomar sua atividade sexual, bem como pode sentir-se insegura e menos desejada. As consequências podem levar a mulher a fazer escolhas baseadas na experiência traumática anterior, como a preferência à cesariana no próximo parto, mesmo com todas suas implicações, como se necessariamente o parto normal viesse acompanhado do corte ${ }^{(2)}$.

Neste estudo, por ter sido realizado durante a internação das puérperas no alojamento conjunto, não se pôde questionar sobre as consequências sexuais destas, porém a literatura aponta que as mulheres têm dificuldade no retorno às atividades sexuais com seus parceiros devido à dor e ao incômodo causado pelo corte. Esse fato pode levar ao desequilíbrio na relação do casal, pois a sexualidade é um 
determinante do bem-estar físico e social, não sendo considerado mais um ato meramente reprodutivo. Reflete-se então sobre as possíveis consequências não somente físicas da episiotomia, mas também psíquicas e sociais ${ }^{(19)}$.

\section{CONSIDERAÇÕES FINAIS}

Observou-se que a maioria das puérperas não recebeu informação sobre a episiotomia no momento do parto, ficando claro seu desconhecimento sobre o procedimento. Isso acarreta uma postura de submissão das parturientes durante o processo do parto e nascimento, tornando-as reféns das decisões e práticas dos profissionais da saúde.

Informar as mulheres a respeito da episiotomia e, principalmente, sobre seus direitos, é fundamental, pois a mulher deve decidir sobre qualquer procedimento de escolha em relação a seu corpo. Por meio do acesso à informação, é possível resgatar a autonomia da mulher no processo de parto e nascimento e em qualquer outra situação que diga respeito às suas escolhas de vida. Dessa forma, também se evita a disseminação de um entendimento errôneo sobre a episiotomia, que, quando utilizada sem critérios, pode ser associada a um procedimento obrigatório e rotineiro durante o parto.

Tanto a Enfermeira como a Enfermeira Obstetra possuem respaldo legal para a realização de partos normais sem distocias, embora essa atividade não seja ainda uma realidade no Brasil. A inserção desse profissional no acompanhamento do pré-natal, parto e puerpério é imprescindível para que o cenário de humanização do cuidado seja incorporado pelas instituições de saúde e pela equipe multiprofissional.

Uma das limitações do presente estudo foi em relação às consequências da episiotomia, pois a maior parte das entrevistadas não teve muitas queixas, talvez por terem sido submetidas ao procedimento recentemente. Assim, sugere-se que estudos futuros sejam realizados com o objetivo de verificar as consequências da episiotomia no longo prazo.

Entende-se que a luta travada para o uso restrito da episiotomia deve ser encorajada a partir das evidências científicas que comprovadamente têm demonstrado que se trata de um procedimento prejudicial quando utilizado de modo assistemático. A mulher deve ser informada e orientada durante o pré-natal sobre o que é e por que é utilizado tal procedimento e os profissionais da saúde devem ser devidamente treinados e atualizados acerca das diretrizes baseadas nas evidências, a fim de contribuir com a diminuição das taxas desnecessárias de episiotomia e suas consequências nocivas à saúde física e psíquica da mulher.

\section{REFERÊNCIAS}

1. Carvalho CCM, Souza ASR, Moraes Filho OB. Episiotomia seletiva: avanços baseados em evidências. Femina [Internet] 2010, 38(5) [acesso em 22 out 2015]. Disponível: http://files.bvs.br/upload/S/0100-7254/2010/v38n5/a008.pdf

2. Figueiredo GS, Santos TTR, Reis CSC, Mouta RJO, Progianti JM, Vargens OMC. Ocorrência de episiotomia em partos acompanhados por enfermeiros obstetras em ambiente hospitalar. Rev. Enferm. UERJ [Internet] 2011, 19 (2) [acesso em 22 out 2015]. Disponível: http://www.facenf.uerj.br/v19n2/v19n2a02.pdf

3. Pitangui ACR, Carvalho NHMG, Siqueira CV, Castro JFL, Araújo RC. Occurrence and factors associated to the practice of episiotomy. Rev enferm UFPE online [Internet] 2014, 8 (2) [acesso em 22 out 2015]. Disponível: http://www.revista.ufpe.br/revistaenfermagem/index.php/revista/article/view/5820/pdf_4520

4. Braga GC, Clementino STP, da Luz PFN, Scavuzzi A, Noronha Neto C, Amorim MMR. Risk factors for episiotomy: a case-control study. Rev. Assoc. Med. Bras. [Internet] 2014, 60(5) [acesso em 22 out 2015]. Disponível: http://www.scielo.br/pdf/ramb/v60n5/0104-4230-ramb-60-05-0465.pdf

5. Carroli G, Mignini L. Episiotomy for vaginal birth (Cochrane review). Cochrane Library, 2009, (1) [acesso em 22 out 2015]. Disponível:

http://www.ncbi.nlm.nih.gov/pmc/articles/PMC4175536/ doi: 10.1002/14651858.CD000081.pub2 
6. Organização Mundial de Saúde (OMS). Maternidade Segura. Assistência ao Parto Normal: um guia prático. Genebra; 1996.

7. Previatti JF, Souza KVS. Episiotomia: em foco a visão das mulheres. Rev. Bras. Enferm. [Internet] 2007, 60 (2) [citado em 22 out 2015]. Disponível: http://www.scielo.br/pdf/reben/v60n2/a12v60n2.pdf

8. Minayo MCS, Deslandes SF, Gomes R. Pesquisa Social: teoria, método e criatividade. 30ª ed. Petrópolis: Vozes; 2011.

9. Ministério da Saúde (BR). Conselho Nacional de Saúde. Diretrizes e normas regulamentadoras de pesquisa envolvendo seres humanos. Resolução n. 466, de 12 de dezembro de 2012. Brasília; 2012. Disponível:

http://conselho.saude.gov.br/resolucoes/2012/Reso466.pdf

10. Costa NM, Oliveira LC, Solano LC, Martins PHMC, Borges IF. Episiotomia nos partos normais: uma revisão de literatura. Facene/Famene [Internet] 2011, 9(2) [acesso em 22 out 2015]. Disponível:

http://www.facene.com.br/wp-content/uploads/2010/11/2011-2-pag-45-50-Episiotomia.pdf

11. Souza VB, Roecker S, Marcon SS. Ações educativas durante a assistência pré-natal: percepção de gestantes atendidas na rede básica de Maringá- PR. Rev Eletr Enf [Internet] 2011, 13(2) [acesso em 22 out 2015]. Disponível: https://www.fen.ufg.br/fen_revista/v13/n2/v13n2a06.htm

12. Quitete JB, Vargens OMC. O poder no cuidado da enfermeira obstétrica: empoderamento ou submissão das mulheres usuárias? Rev. Enferm. UERJ [Internet] 2009, 17(3) [acesso em 02 nov 2015]. Disponível:

http://www.facenf.uerj.br/v17n3/v17n3a03.pdf

13. Malheiros PA, Alves VH, Rangel TSA, Vargens OMC. Parto e nascimento: saberes e práticas humanizadas. Texto Contexto Enferm. [Internet] 2012, 21(2) [acesso em 02 nov 2015]. Disponível:

http://www.scielo.br/pdf/tce/v21n2/a10v21n2.pdf

14. Ministério da Saúde (BR). Lei 7.498, de 25 de junho de 1986. Dispõe sobre a Regulamentação do Exercício da Enfermagem e dá outras providências. Brasília, 26 jun. 1986. Disponível em:

http://www.abennacional.org.br/download/LeiPROFISSIONAL.pdf

15. Davis-Floyd R. The technocratic, humanistic, and holistic paradigms of childbirth. Int J Gynaecol Obstet [Internet] 2001, 75 Suppl 1 [acesso em 13 nov 2015]. Disponível: http://www.dendimim.com.br/public/Material\%20 de $\% 20$ leitura/Modelos $\% 20$ tecnocr $\%$ C3\%A1tico $\% 20$ human $\%$ C3\%ADstico $\% 20$ e $\% 20$ hol\%C3\%ADstico $\% 20$ no\%20parto.pdf

16. Hatem M, Sandall J, Devane D, Soltani H, Gates S. Midwife-led versus other models of care for childbearing women. Cochrane Database Syst Rev. 2008; (4): CD004667. Disponível:

http://apps.who.int/rhl/reviews/langs/CD004667.pdf

17. Silva TF, Costa GAB, Pereira ALF. Cuidados de enfermagem obstétrica no parto normal. Cogitare Enferm. [Internet] 2011, 16(1) [acesso em 10 fev 2016]. Disponível:

http://ojs.c3sl.ufpr.br/ojs2/index.php/cogitare/article/view/21116/13942

18. Amorim MMR, Katz L. O papel da episiotomia na obstetrícia moderna. Femina [Internet] 2008, 36(1) [acesso em 22 out 2015]. Disponível: http://institutonascer.com.br/wp-content/uploads/2014/03/episio_femina.pdf

19. Progianti JM, Araújo LM, Mouta RJO. Repercussões da episiotomia sobre a sexualidade. Esc. Anna Nery [Internet] 2008, 12(1) [acesso em 22 out 2015]. Disponível: http://www.scielo.br/pdf/ean/v12n1/v12n1a07.pdf 